\title{
In situ implantation of a valved femoral vein allograft in a neonate with pulmonary atresia with intact ventricular septum and severe tricuspid regurgitation
}

Arata Murakami, MD, ${ }^{a}$ Tetsuhiro Takaoka, MD, ${ }^{a}$ Jyotaro Kobayashi, MD, ${ }^{a}$ Katsuhide Maeda, MD, ${ }^{a}$ Tetsufumi Yamamoto, MD, ${ }^{a}$ Noboru Motomura, MD, ${ }^{a}$ Shinichi Takamoto, MD, ${ }^{a}$ Hiroko Sugimura, MD, ${ }^{\mathrm{b}}$ Kazuhiko Shibuya, MD, ${ }^{\mathrm{b}}$ Hitoshi Kato, MD, ${ }^{\text {b }}$ and Shigeo Yamaki, MD, ${ }^{\mathrm{c}}$ Tokyo and Shiroishi, Japan

W e report a case of pulmonary atresia with intact ventricular septum and severe tricuspid regurgitation in a neonate who was treated by in situ implantation of a valved femoral vein allograft in the anatomic position to eliminate pulmonary regurgitation and to augment forward flow into the highly resistant and hypoplastic pulmonary circulation.

\section{Clinical Summary}

At 38 weeks' gestation, a 2334-g boy was delivered by cesarean section. Oxygen saturation of arterial blood $\left(\mathrm{SaO}_{2}\right)$ was $80 \%$ with room air, and the cardiothoracic ratio was 0.92 . Echocardiography demonstrated a dysplastic tricuspid valve, which showed nodular and echodense valvular tips and a tethered septal leaflet, no forward flow across the pulmonary valve without regurgitant signals, and patent ductus arteriosus. Alprostadil administration was started. The Great Ormond Street Ebstein echocardiogram score ${ }^{1}$ was 0.58 , grade 2 . On postnatal day 1 , the unwell neonate required endotracheal intubation. On postnatal day 3 , an emergency right hemicolectomy was done to treat meconium peritonitis. Instability of the systemic circulation and progression of the cardiomegaly indicated surgical intervention for the congenital heart defects on postnatal day 14 .

A mildly hypothermic cardiopulmonary bypass was instituted. After patent ductus arteriosus ligation, the heart was arrested by infusion of blood cardioplegic solution. The main pulmonary artery (PA) was transected at just above the sinotubular junction, and the atretic membrane was removed. As a result, a dilator of $9 \mathrm{~mm}$ was permitted to pass into the right ventricular (RV) outflow. A femoral vein allograft containing a bicuspid competent valve with an external diameter of $8 \mathrm{~mm}$ (supplied by the University of Tokyo Tissue Bank, Tokyo, Japan) was thawed. A segment of the allo-

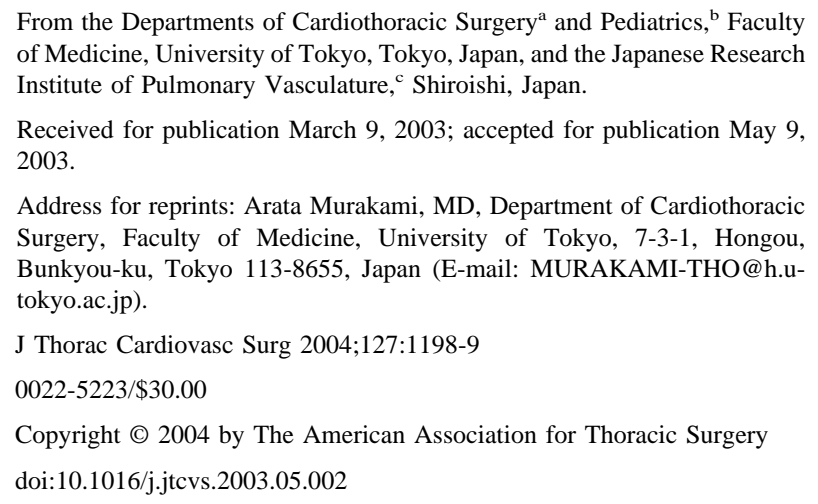

graft with the valve was interposed between the proximal and distal PA stumps (Figure 1), and the pump was terminated. The myocardial ischemic time was 22 minutes. $\mathrm{SaO}_{2}$ was $67 \%$ with $100 \%$ inspired oxygen and $10 \mathrm{ppm}$ nitric oxide gas inhalation. Central venous pressure was $16 \mathrm{~mm} \mathrm{Hg}$. Systemic arterial blood pressure was 53/28 mm Hg with $10 \gamma$ dobutamine and dopamine and $0.2 \gamma$ epinephrine. A peritoneal dialysis catheter was inserted. Forward flow through the allograft was confirmed by transesophageal echocardiography. Regurgitant signals through the valve were trivial. During the night of the same day, $\mathrm{SaO}_{2}$ dropped despite 20 ppm inhaled nitric oxide. Echocardiography demonstrated dynamic RV outflow tract obstruction. The patient underwent right modified Blalock-Taussig shunt (BTS) with a $3.5-\mathrm{mm}$ polytetrafluoroethylene graft the next day.

Back distribution of peritoneal dialysis fluid forced us to introduce continuous venovenous hemofiltration. On the second postoperative day, cardiothoracic ratio, $\mathrm{SaO}_{2}$, and central venous pressure were improved $(75 \%, 82 \%$, and $8 \mathrm{~mm} \mathrm{Hg}$, respectively) with the same respirator conditions and without nitric oxide inhalation. Thereafter, however, the patient developed sepsis and disseminated intravascular coagulopathy, resulting in hemodynamic deterioration. The patient died on the 15 th postoperative day. Postmortem examination demonstrated widely patent $\mathrm{RV}$ outflow with modified BTS. Histologic examination of the lung revealed severe pulmonary vascular disease, which showed thickening of the intima but not the media (Figure 2).

\section{Discussion}

The outlook for the neonate with tricuspid regurgitation with severe cardiomegaly is generally poor. Yamaki and colleagues ${ }^{2}$ examined lungs from neonates with severe tricuspid regurgitation, revealing that the lung hypoplasia and mean medial thickness of the small pulmonary arteries were more similar to those in a control group than to those in neonates with a diaphragmatic hernia. Although the procedure reported by Starnes and coworkers $^{3}$ has palliated the condition of these patients, if at all possible salvaging the RV should be a goal in view of the long-term functional advantage. Recently we reported the feasibility of a saphenous vein valved allograft as RV-PA conduit in the modified Norwood operation. ${ }^{4}$ This experience encouraged us to use a valved femoral vein allograft. In this case, dynamic RV outflow tract obstruction interfered with effective forward flow, and eventually BTS was required. Nevertheless, in situ implantation combined with or without BTS is recommended for a selected subgroup of patients with this anomaly, rather than use of an extracardiac RV-PA conduit, because RV outflow reconstruction 


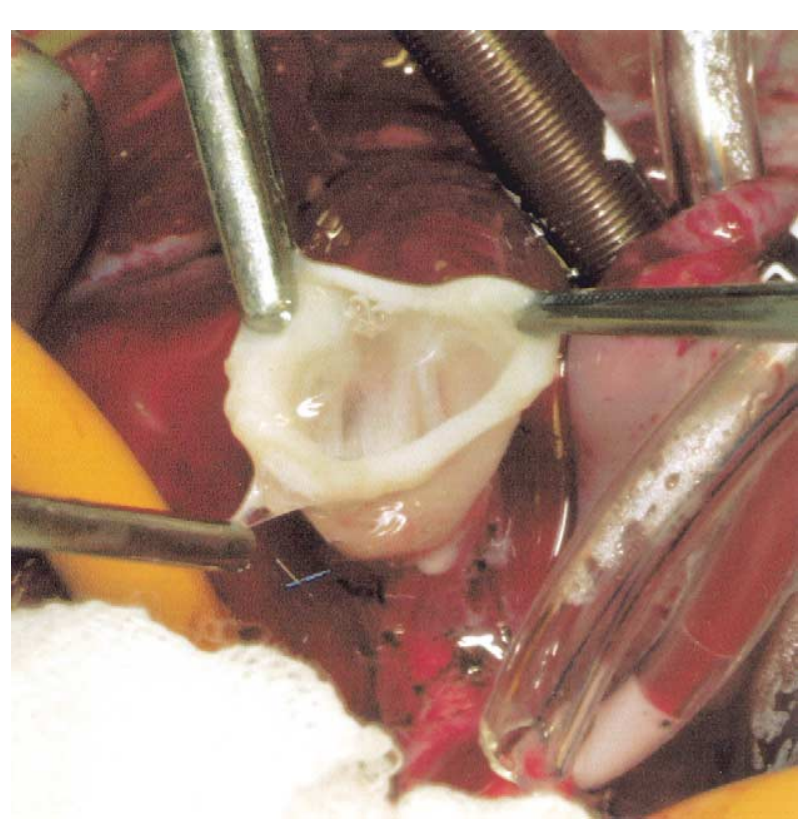

Figure 1. Segment of femoral vein allograft containing competent valve was anastomosed to proximal PA stump.

in a physiologic route will yield laminar flow through the allograft, thus allowing superior longevity. ${ }^{5}$

From the histologic report on the lung, severe pulmonary hypertension was suggested in this case. This informed us of the wide range variation of the structural changes of the pulmonary vasculature and also made us aware that the optimal treatment for this anomaly should be discussed on a case-by-case basis.

We thank Ms Sakiko Shibusawa and Dr Hiroo Takayama for their help in shipping and thawing the allograft.

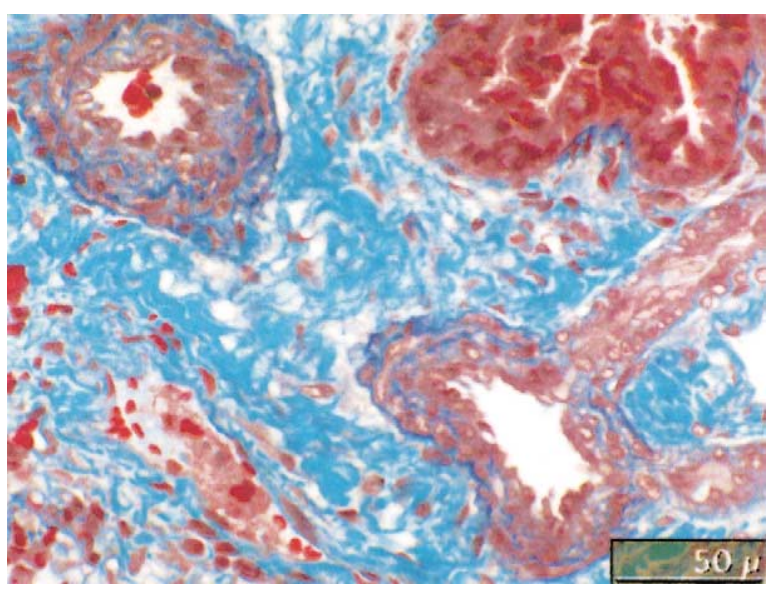

Figure 2. Two pulmonary arterioles $70 \mu \mathrm{m}$ in diameter show cellular and fibrous thickening of intima. Medial thickening was not notable.

\section{References}

1. Celermajer DS, Bull C, Till JA, Cullen S, Assillikos VP, Sullivan ID, et al. Ebstein's anomaly: presentation and outcome from fetus to adult. J Am Coll Cardiol. 1994;23:170-6.

2. Tanaka T, Yamaki S, Ohno T, Ozawa A, Kakizawa H, Linuma K. The histology of the lung in neonates with tricuspid valve disease and gross cardiomegaly due to severe regurgitation. Pediatr Cardiol. 1998;19: 133-8.

3. Starnes VA, Pitlick PT, Bernstein D, Griffin ML, Choy M, Shumway N. Ebstein's anomaly appearing in the neonate. J Thorac Cardiovasc Surg. 1991;101:1082-7

4. Murakami A, Takamoto S, Takaoka T, Kobayashi J, Maeda K, Takayama H, et al. Saphenous vein homograft containing a valve as a right ventricle-pulmonary artery conduit in the modified Norwood operation. J Thorac Cardiovasc Surg. 2002;124:1041-2.

5. Tweddell JS, Pelech AN, Frommelt PC, Mussatto KA, Wyman JD, Fedderly RT, et al. Factors affecting longevity of homograft valves used in right ventricular outflow tract reconstruction for congenital heart disease. Circulation. 2000;102(Suppl 3):III130-5. 